\title{
Surgical Repair of Uterine Prolapse in a Queen Cat: A Case Report
}

\author{
Keshav Kumar*, Kalyani Ray, Durga Das Mandal, Pradeep Sarkar, \\ Surajit Das and Ajeet Kumar Jha
}

\begin{abstract}
Department of Veterinary Gynaecology \& Obstetrics, Veterinary and Animal Sciences West Bengal University of Animal and Fishery Sciences, 37K. B. Sarani, Kolkata-700037, West Bengal, India
\end{abstract}

*Corresponding author

\section{A B S T R A C T}

\section{Keywords}

Uterine prolapsed, Queen cat, Ovario hysterectomy

Article Info

Accepted: 18 April 2020 Available Online: 10 May 2020
A queen cat of one year age having $3.2 \mathrm{Kg}$ body weight was admitted to Veterinary clinical complex, WBUAFS, Belgachia, Kolata with the history of protrution of uterine horn through vulva. Case history revealed that the cat whelped 4 kitten two days ago and after physical examination uterine prolapsed was diagnosed. Hence, we repaired the prolapse by ovariohysterectomy with general anaesthesia. Present article explain the method of successful management of uterine prolapse in queen cat.

\section{Introduction}

Uterine prolapse is a relatively uncommon complication of parturition, occurring infrequently in cats and rarely in dogs (Deroy et al., 2015, Özyurtlu and Kaya, 2005). It occurs immediately or up to $48 \mathrm{~h}$ after delivery of the last neonate (Johnston et al., 2001, Bigliardi et al., 2014).

A one year old queen cat weighing $3.2 \mathrm{~kg}$ was presented to the veterinary clinics with a history of uterine prolapsed. An emergency surgery was planned to treat uterine prolapsed with ovariohysterectomy. Animal become anaesthetized with a mixture of injection ketamine $(8 \mathrm{mg} / \mathrm{kg})$ and xylaxine $(1 \mathrm{mg} / \mathrm{kg})$ was used intramuscular route.

After induction, the surgical site was prepared by clipping the hair of dorsal abdomen. After preparation of the surgical site povidone iodine was applied as antiseptic lotion. An incision was made on middle abdomen.

The prolapsed mass (Fig. 1A) was cleaned 
with povidone iodine and LOX gel $^{\circledR}$ (Lignocaine Hydrochloride) was applied as local anaesthetic as well as lubricant. Cervix, Overies and muscle were ligated with petcryl(2-0) (Fig. 1B).

Simple continuous suture were done to close the muscle. Simple interrupted suture were given to close the skin (Fig. 1C) by linex ${ }^{\circledR}(1-$
0) (Nylon). After wound closure, gentamycin lotion was applied locally and a protective bandage was made (Fig. 1D). Post-operatively cefotaxime injection @ $20 \mathrm{mg} / \mathrm{kg}$ intramusculary twice a day for 5 days, relaxzyme @1 tablet twice a day for 3 days, rantidine tablet @3mg/kg twice a day for 5 days.
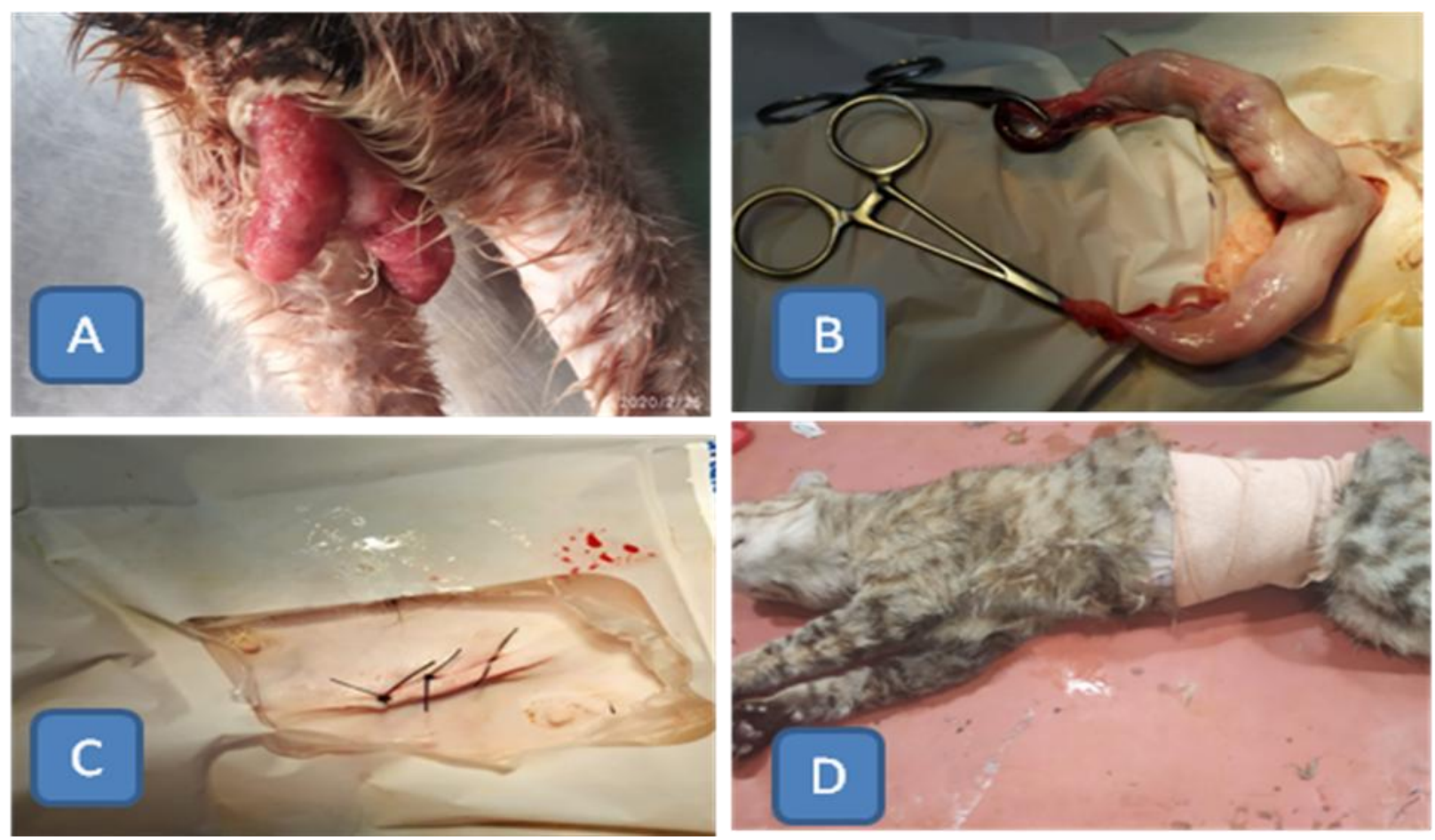

Fig.1 Occurrence and surgical removal of uterine prolapse in queen cat which includes

A. Prolapse of Uterus in queen cat extruding out of vulva.

B. Protruded uterine horn corrected surgically with incision made at lower abdomen.

C. After surgical correction simple interrupted skin suture is applies with Linex ${ }^{\circledR}$.

D. Post-operative bandage is applied after skin suture at lower abdomen.

The case was followed upto 10 days after ovariohysterectomy and postoperative dressing were done on every alternate day. On $10^{\text {th }}$ post-operative day skin suture were removed as the healing was found uneventful.

\section{References}

Bigliardi E., Di Ianni F., Parmigiani E., Cantoni AM., Bresciani C. (2014). Complete uterine prolapse without uterine mucosal eversion in a queen. Journal of Small Animal Practice, 55(4), 235-237.

Deroy C., Bismuth C., Carozzo C. (2015). Management of complete uterine prolapse in a cat. Journal of Feline Medicine and Surgery Open Reports, 1 (1), 1-4.

Johnston SD., Kustritz MVR., Olson PNS. (2001). The postpartum period in the cat. Canine and Feline Theriogenology. 
1st ed. Philadelphia, PA, USA: WB Saunders Company. 442.

Özyurtlu N., Kaya D. (2005). Unilateral prolapse in a cat. Turkish Journal of Veterinary and Animal Sciences; 29 (2005), 941-943.

\section{How to cite this article:}

Keshav Kumar, Kalyani Ray, Durga Das Mandal, Pradeep Sarkar, Surajit Das and Ajeet Kumar Jha. 2020. Surgical Repair of Uterine Prolapse in a Queen Cat: A Case Report. Int.J.Curr.Microbiol.App.Sci. 9(05): 2609-2611. doi: https://doi.org/10.20546/ijcmas.2020.905.298 